\title{
Mesomorphic Behavior of Concentrated Solutions of Polyribonucleotides
}

\author{
Eisaku IızUKA
}

Institute of High Polymer Research, Faculty of Textile Science
and Technology, Shinshu University, Ueda, Nagano 386, Japan

(Received February 15, 1983)

\begin{abstract}
Concentrated solutions of polyribonucleotides, poly(A), poly(G), poly(I), poly $(\mathrm{C})$, and poly(U), were studied by polarizing micrography, diffraction of laser light, visible absorptivity, circular dichroism, X-ray diffraction, and viscometry. The experimental data obtained suggest that these homopolymer molecules aggregate to form liquid crystals when in ordered conformations and that except those of poly $(\mathrm{G})$, the liquid crystals are chiral and probably of the cholesteric type. The helical sense of the chiral texture varies with polyribonucleotides.

KEY WORDS Polyribonucleotide / Helical Conformation / Liquid Crystal /

Cholesteric Phase / Helical Sense / Viscosity / Circular Dichroism /
\end{abstract}

Recently, the author reported that the doublestranded helices of $\operatorname{poly}(\mathrm{A}) \cdot \operatorname{poly}(\mathrm{U})$, $\operatorname{poly}(\mathrm{G})$. poly $(\mathrm{C})$, and poly $(\mathrm{C}) \cdot \operatorname{poly}(\mathrm{I})$ and the triple-stranded helices of poly(A) 2 poly(U) and poly(A) 2 poly(I) in concentrated solutions formed nematic liquid crystals. The molecular clusters forming the liquid crystals of the two complexes of poly(A) and poly(U) were rod-like. In each molecular cluster the long axes of the polymer helices were parallel to the rod axis. On standing, these nematic liquid crystals became cholesteric. ${ }^{1,2}$ The nematic liquid crystals reconstructed from the cholesteric liquid crystals by slight shearing were oriented by a static magnetic field, with the polymer helices perpendicular to the magnetic field. This suggests that the maximum magnetic susceptibility of these diamagnetic polymer molecules is in the direction of the polymer helices. ${ }^{1,3}$

In this paper, the author shows that individual polyribonucleotides also can form liquid crystals when in an ordered conformation and discusses the liquid crystalline properties in some detail.

\section{EXPERIMENTAL}

\section{Materials}

Potassium salts of poly(A), poly(C), and poly(U) were purchased from P-L Biochemicals, Inc.; the lot numbers were 441102,942201 , and 444401 , respectively. A sodium salt of $\operatorname{poly}(\mathrm{G})$ and a potassium salt of poly(I), both from Miles laboratories, Inc., were donated by Prof. J. T. Yang of Cardiovascular Research Institute, University of California-San Francisco; the code numbers were 11-314 and 1139-307, respectively. The sedimentation coefficient, $s_{20, w}$, was 6-13 for poly(A) and $\operatorname{poly}(\mathrm{C})$ and 5-12 for poly(U). Judging from these figures, the molecular weights of these samples were fairly high.

All the polyribonucleotides were dissolved in $0.08 \mathrm{M} \mathrm{NaCl}$ and $0.02 \mathrm{M}$ sodium citrate plus citric $\operatorname{acid}^{4}$ with a pH of 7.0 for $\operatorname{poly}(\mathrm{G})$, poly(I), and poly $(\mathrm{U})$, and a $\mathrm{pH}$ of 4.5 for poly(A) and poly $(\mathrm{C})$. $0.01 \mathrm{M} \mathrm{MgCl}_{2}$ was added to the poly $(\mathrm{U})$ solutions. The concentrated solutions were stored for at least two weeks at $5^{\circ} \mathrm{C}$ prior to measurements to insure full growth of the liquid crystals.

\section{Methods}

The solutions were placed in quartz cells of $1-\mathrm{mm}$ pathlength, and a quartz spacer was inserted into each cell to reduce the lightpath to about $0.1 \mathrm{~mm}$ or less. Then the solutions were kept at least overnight prior to measurements. Since poly $(G)$ and poly(I) became gel-like at high concentrations, the solutions were preheated to about $70^{\circ} \mathrm{C}$ to release the 
tension resulting from the insertion of the spacer (or to make them isotropic) and cooled to room temperature.

Micrographs of the solutions were taken between crossed polarizers, and the light scattering (low angle) patterns were obtained using a $2-\mathrm{mW} \mathrm{He}-\mathrm{Ne}$ gas laser $(6328 \AA)$ as the light source. Circular dichroism (CD) was measured with a Jasco J-40A spectropolarimeter and visible-ultraviolet absorption with a Jasco ORD/UV-5 spectropolarimeter. $\mathrm{CD}$ was also measured on polyribonucleotide solutions containing an achiral dye, acridine orange (AO), at a concentration of 1 part per $80-150$ parts of polyribonucleotide. Two $\mathrm{CD}$ curves measured $90^{\circ}$ apart at the angle about the axis parallel to the incident beam and perpendicular to the surface of the optical cell, were averaged to eliminate any effects of possible linear dichroism of the solution according to Schneider and Maestre. ${ }^{5}$ This procedure was applied only to birefringent solutions. X-Ray diffraction (wide angle) patterns of solutions in quartz capillary tubes of $1-\mathrm{mm}$ diameter were photographed using a Rigaku Denki geigerflex $\left(35 \mathrm{kV}, 25 \mathrm{~mA}, \mathrm{Cu} K_{\alpha}\right.$ line). Steady-state viscosities were measured on a cone-and-plate rheogoniometer manufactured by Iwamoto Seisakusho Co., Ltd. The viscosity measurement was also made on the two complexes of poly(A) and poly(U) prepared as described elsehwere. ${ }^{1}$

Unless otherwise stated, all measurements were carried out at room temperature $\left(22^{\circ} \mathrm{C}\right)$ except for the poly $(\mathrm{U})$ solutions $\left(2{ }^{\circ} \mathrm{C}\right)$. The density of the polyribonucleotides was assumed to be $1.6 \mathrm{~g} \mathrm{~cm}^{-3}$.

\section{RESULTS AND DISCUSSION}

\section{Microscopic Observation and Light Scattering}

Test solutions of polyribonucleotide became slightly turbid and concurrently birefringent at a certain polymer concentration, about $1 \mathrm{vol} \%$ for poly(A), about $5 \mathrm{vol} \%$ for $\operatorname{poly}(\mathrm{G})$ and poly(I), and about $20 \mathrm{vol} \%$ for poly(C) and poly(U). Figure 1 shows the polarizing micrographs of the birefringent solutions.

As for poly(A), spherulitic droplets appear first in the isotropic phase. Their number and size increase with increasing polymer concentration and finally the droplets coalesce with each other to form a uniform birefringent phase (Figure 1, A(1)-(3)). This change is very similar to that observed with poly $\left(\gamma\right.$-benzyl glutamate) (PBG) by Robinson. ${ }^{6}$ The arms of the maltese cross in the spherulites are parallel to the principal planes of the polarizers, and it can be shown with a compensator that the higher refractive index is in the radial rather than the tangential direction. Since the higher refractive index is in a direction perpendicular to the rod-like polyribonucleotide molecule, it may be considered that the molecules are arranged tangentially in the spherulites. Because of the presence of spherulitic structure, the $H_{\mathrm{v}}$ light scattering pattern is of the four-leafed clover type as can be seen in Figure 2. With increasing polymer concentration, the pattern gradually loses this feature (Figure 2, A(1)-(3)).

The other polyribonucleotides show behavior somewhat different from poly(A). Poly(G) and poly $(U)$ show the presence of spherulites in which the polymer molecules are aligned tangentially as in poly(A). Poly(G) exhibits a nematic-like pattern in the polarizing micrograph (Figure 1, G) and the $H_{\mathrm{v}}$ scattering pattern of the $\pm 45^{\circ}$ type (Figure 2, G). The latter pattern is characteristic of a rod-like aggregate of polymer molecules in ordered conformations. ${ }^{7,8}$ As for poly $(U)$, the scattering pattern is featureless. However, it changes to the distorted $\pm 45^{\circ}$ type when the solution is sheared slightly (Figure 2, U(2)). This pattern appeared when spherulites collapsed to a rod-like texture aligning in the direction of the shearing stress. ${ }^{9}$ As for poly $(\mathrm{I})$ and poly $(\mathrm{C})$, no characteristic feature was found in either the polarizing micrograph or light scattering pattern.

\section{Viscosity}

The viscosity of the concentrated solutions of polyribonucleotides decreased with increasing shear rate. This decrease may be caused by a collapse of the three dimensional structure originally present in the solution at low shear rates and by orientation of polymer aggregates at high shear rates.

Figure 3 shows the changes in reduced viscosity, $\eta_{\mathrm{sp}} / c$, with polymer concentration. The reduced viscosity of poly(A) first displays a drastic increase and decreases sharply after reaching a maximum value. The polymer concentration at the viscosity maximum agrees with the appearance of the birefringent phase in the isotropic solutions. This agreement is characteristic of the isotropic-to-liquid crystalline transition as was the case for the solutions of PBG and of poly $\left(\gamma\right.$-ethyl glutamate).$^{10}$ Poly $(G)$ 

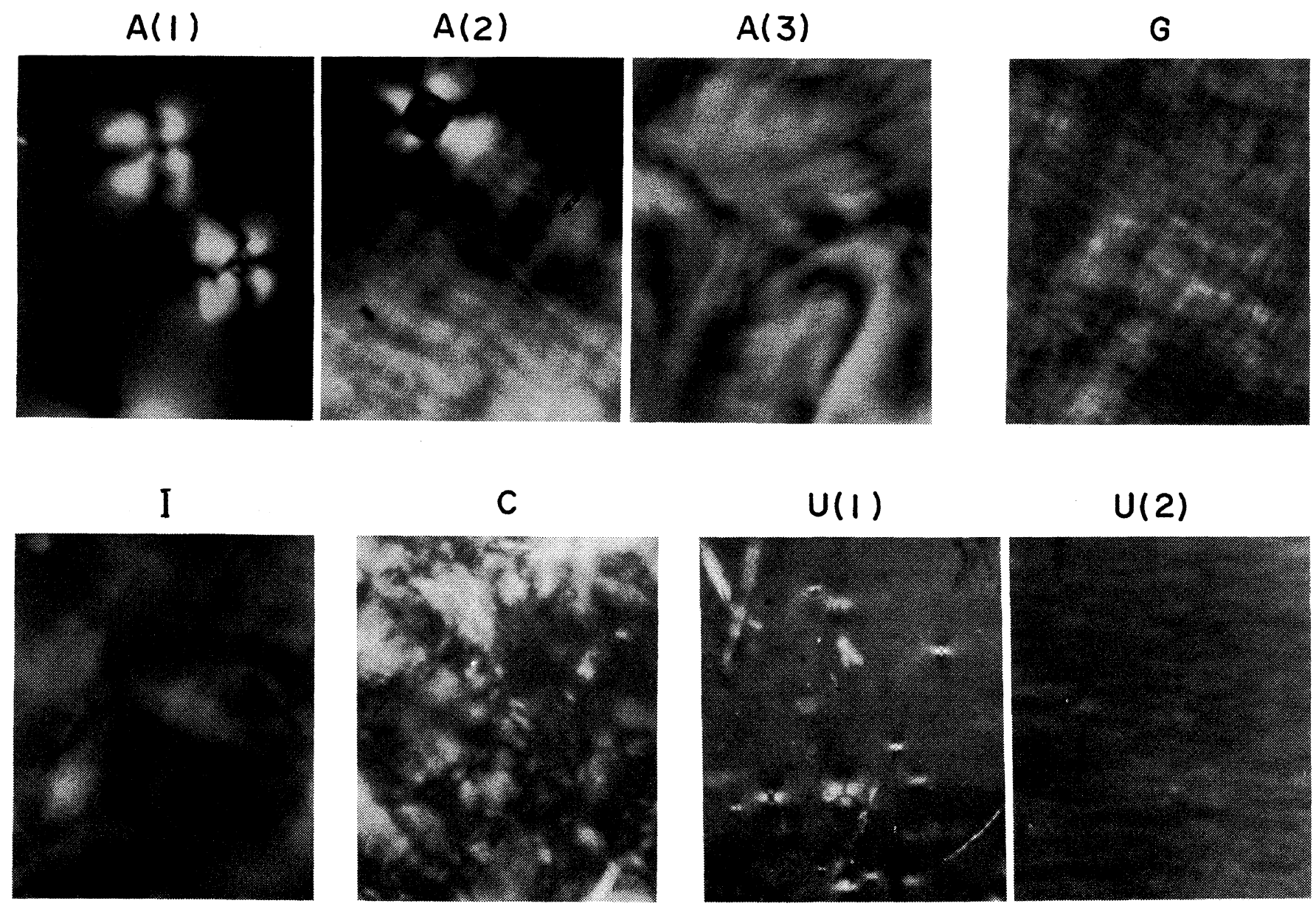

Figure 1. Polarizing micrographs of concentrated solutions: A, poly(A), (1) $1.9 \mathrm{vol} \%$; (2) $2.4 \mathrm{vol} \%$; (3) $3.1 \mathrm{vol} \%$; G, poly(G), 8.2 vol\%; I, poly(I), 5.5 vol\%, C, poly(C), 28 vol\%; U, poly(U), 28 vol\%; (1) not sheared; (2) sheared vertically. 


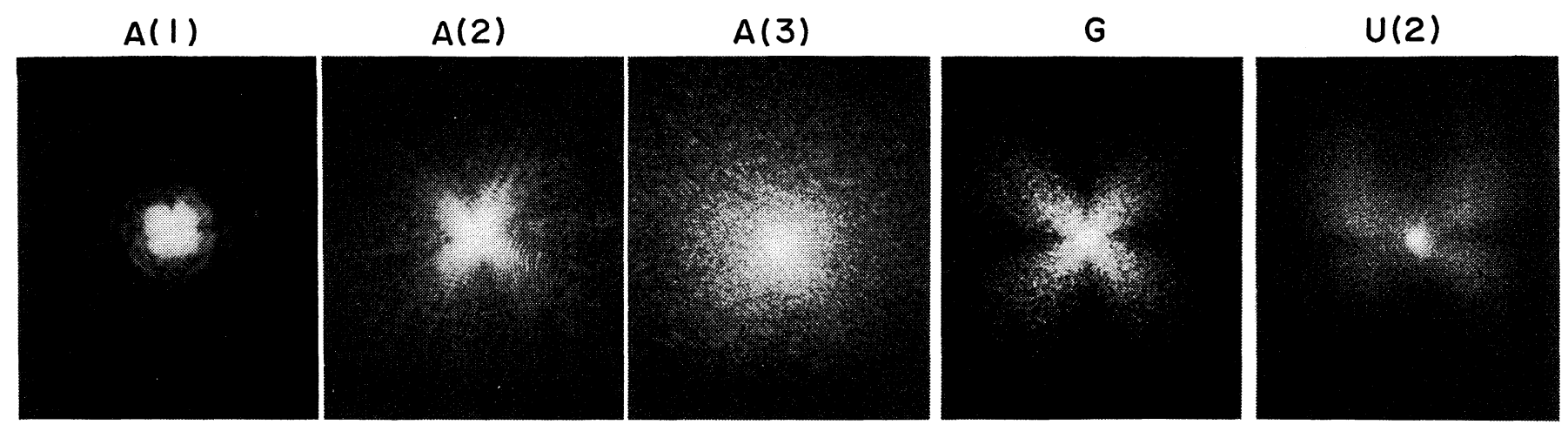

Figure 2. $H_{\mathrm{v}}$ light scattering patterns of concentrated solutions. Symbols are the same as in Figure 1. 


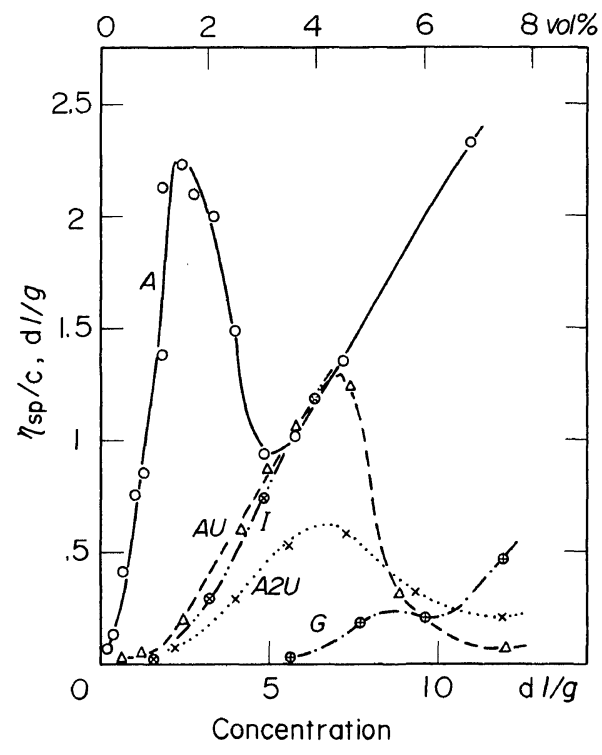

Figure 3. Reduced viscosity $v s$. polymer concentration relationship. A, poly(A); G, poly(G); I, poly(I); AU, $\operatorname{poly}(\mathrm{A}) \cdot \operatorname{poly}(\mathrm{U}) ; \mathrm{A} 2 \mathrm{U}$, poly(A) $2 \operatorname{poly}(\mathrm{U})$. Measured at $22^{\circ} \mathrm{C}$ and a shear rate of $6.8 \mathrm{~s}^{-1}$.

shows a viscosity maximum though not markedly, and poly(I) shows a monotonic increase in reduced viscosity; however, no further measurement was carried out because of gelation. The two complexes of poly(A) and poly(U), which have already been shown to become liquid crystalline, ${ }^{1}$ exhibited the typical relationship between reduced viscosity and concentration.

\section{$X$-Ray Diffraction}

Figure 4 shows some of the wide-angle X-ray diffraction photographs of the birefringent solutions and films of polyribonucleotides. DebyeScherrer rings are seen for both solutions and films, indicating that the polymer molecules are in some ordered conformation and arranged in some specific way. The inner rings related to the arrangement of polymer molecules are more diffuse in the solutions than in the films. The corresponding spacings are larger in the solutions as can be seen from Table I. These findings suggest that in solution, the polymer molecules are more separated and arranged less orderly, and, together with the above-stated microscopic observations and the viscosity data, may be considered to indicate that the concentrated so- lutions of polyribonucleotide are liquid crystalline. The occurrence of gelation in poly $(\mathrm{G})$ and poly $(\mathrm{I})$ cannot be explained.

The 3.8- $\AA$ spacing of poly(A) may correspond to the stacked bases of the double-stranded helix which has a pitch of $30.4 \AA$ with 8 bases per turn as proposed by Rich and his coworkers. ${ }^{11}$ The DebyeScherrer ring corresponding to a $3.4-\AA$ spacing may be related to the stacked bases of the polymer helix nearly normal to the helical axis in poly $(G)$ and to the helical pitch of $29.4 \AA$ with 8.65 bases per turn in poly(I). The former may take on a conformation similar to the B-form of DNA, ${ }^{12}$ and the latter, the triple-stranded helix proposed by Rich. ${ }^{13} \operatorname{Poly}(\mathrm{C})$ has been shown to be in a double-stranded helix at acidic $\mathrm{pH}^{14}$ and the corresponding characteristic spacing may be $3.2 \AA$. Poly $(U)$ is randomly coiled at room temperature and at neutral $\mathrm{pH} .{ }^{15}$ However, Lipsett $^{16}$ suggests that poly(U) becomes helical (probably double-stranded) at temperatures below $5^{\circ} \mathrm{C}$ and with the addition of $0.01 \mathrm{M} \mathrm{MgCl}_{2}$. The solution of poly $(U)$ shows weak Debye-Scherrer rings, indicating the formation of some ordered conformation and some arrangement of the polymer molecules.

\section{Pitch-Band Circular Dichroism}

Figure 5 shows some of the CD spectra of the concentrated solutions both with and without AO. All the birefringent solutions except those of poly $(G)$ without $A O$ showed $C D$. When $C D$ was observable without $\mathrm{AO}$, its intensity increased monotonicaly as the wavelength became shorter. The $C D$ of poly(A) was positive and those of $\operatorname{poly}(\mathrm{I})$, poly $(\mathrm{C})$, and $\operatorname{poly}(\mathrm{U})$ were negative. No maximum (or minimum) was found in the region between 650 and $300 \mathrm{~nm}$. No CD appeared in poly $(\mathrm{G})$ solutions even two weeks after introduction into the optical cell.

Robinson $^{17}$ suggested that a cholesteric liquid crystal reflects the circularly polarized light of one sense selected by the helical sense of the helicoidal texture. This causes the appearance of a new CD known as the pitch-band $C D$. When the incident beam is perpendicular to the nematic like layers, the wavelength at the reflectivity maximum (and the intensity maximum of $\mathrm{CD}$ ), $\lambda_{\mathrm{m}}$, is related to the pitch, $P$, of the helicoidal texture by $\lambda_{\mathrm{m}}=n \times P,{ }^{18}$ where $n$ is the average refractive index of the medium. A $30-\mathrm{vol} \%$ solution of $\operatorname{poly}(\mathrm{A}) \cdot \operatorname{poly}(\mathrm{U})$ 
$A(1)$

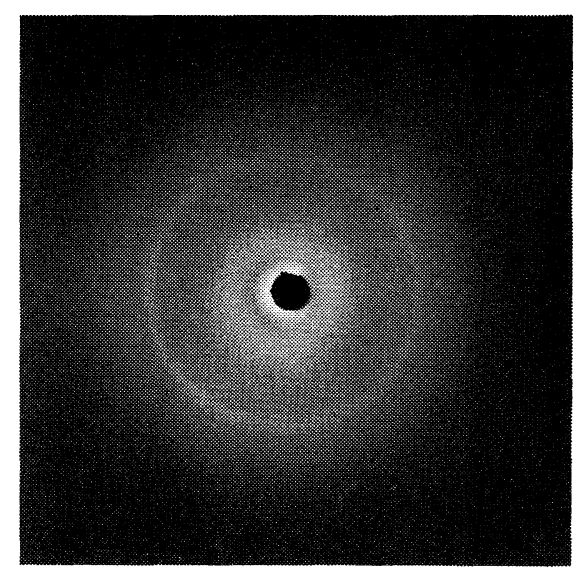

I

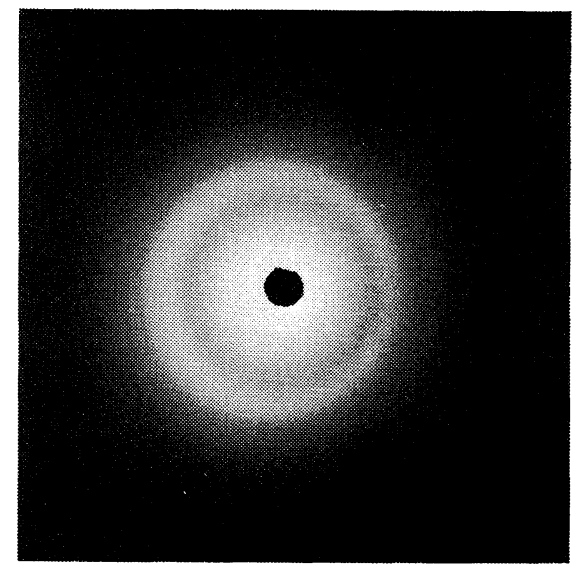

$A(2)$

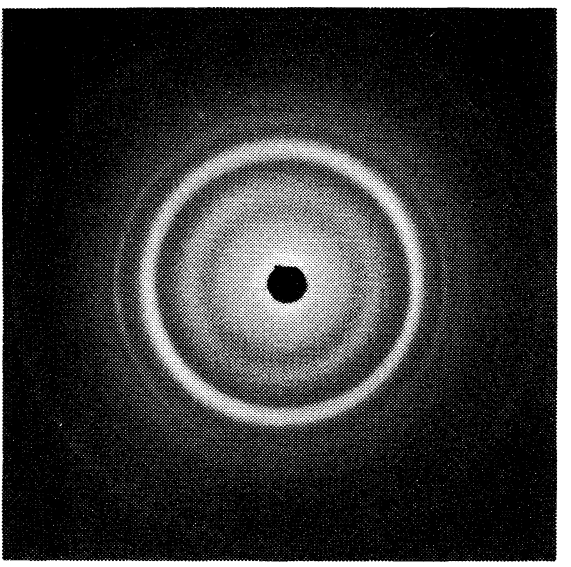

C

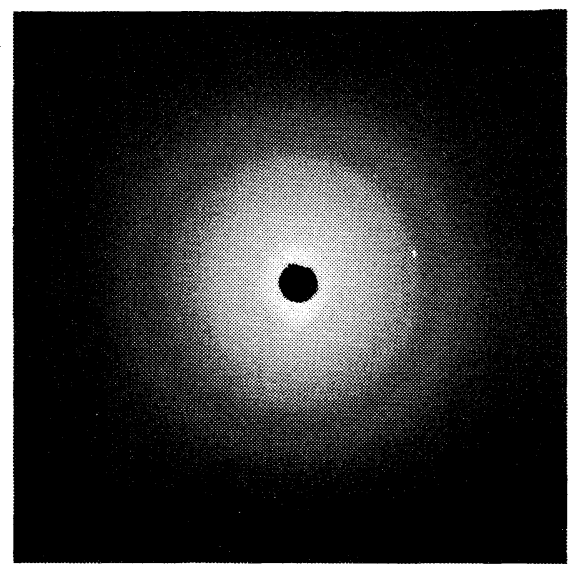

G

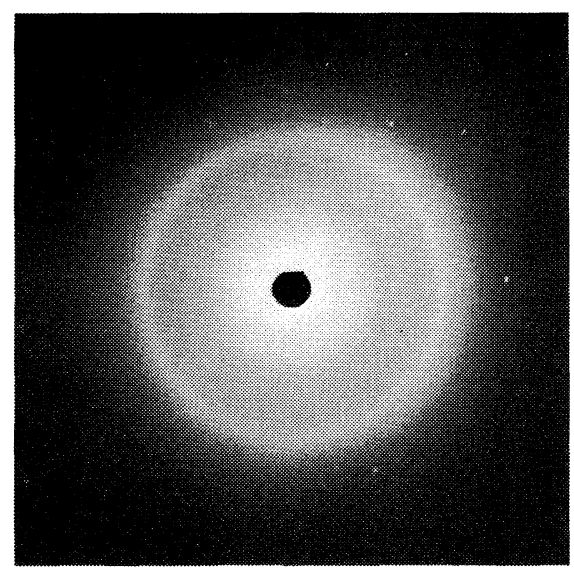

U

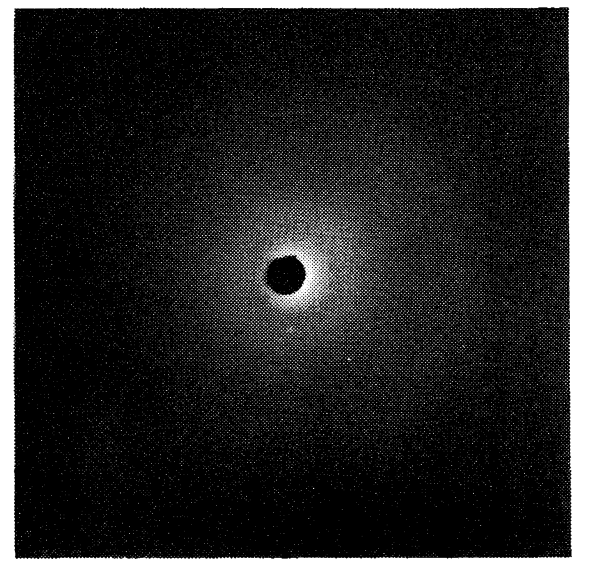

Figure 4. X-Ray diffraction photographs of concentrated solutions and a film. A, poly(A), (1) 10.5 vol\%, (2) solid film; G, poly(G), $15 \mathrm{vol} \%$; I, poly(I), $12.8 \mathrm{vol} \%$; C, poly(C), $28 \mathrm{vol} \%$; U, poly(U), $50 \mathrm{vol} \%$. Measured at $22^{\circ} \mathrm{C}$ except for poly(U) $\left(2^{\circ} \mathrm{C}\right)$. 
Table I. Spacings of polyribonucleotides ${ }^{\mathbf{a}}$

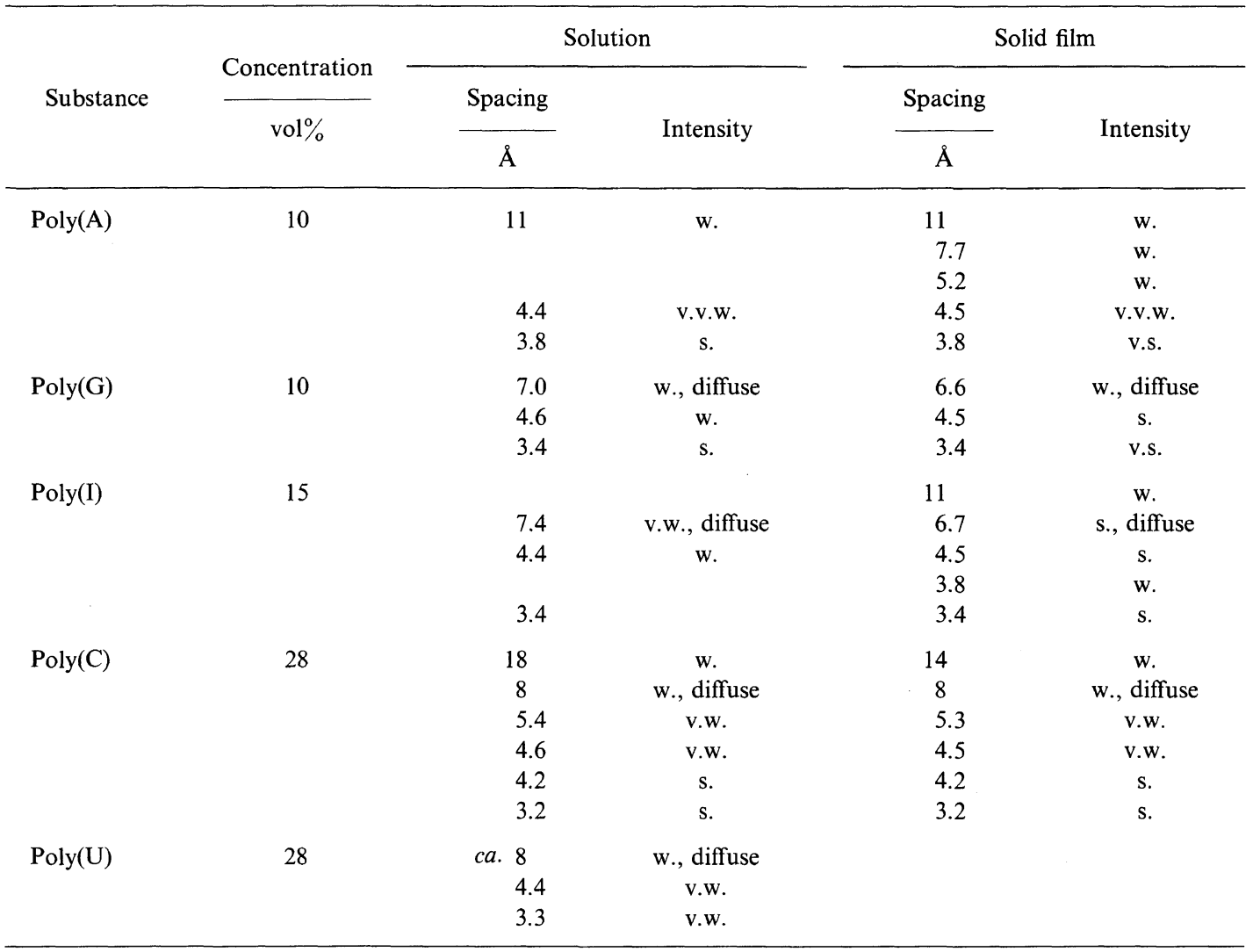

a The $\mathrm{pH}$ of the solution was 4.5 in poly $(\mathrm{A})$ and poly $(\mathrm{C})$ and 7.0 in poly $(\mathrm{G})$, poly(I) and poly(U). The experiment was carried out at $22^{\circ} \mathrm{C}$ except for the poly(U) solution $\left(2^{\circ} \mathrm{C}\right.$, with $\left.0.01 \mathrm{M} \mathrm{MgCl}_{2}\right)$.

showed a negative pitch-band CD centered at about $670 \mathrm{~nm}$ and the helical sense of the cholesteric texture was assigned as right-handed ${ }^{2}$ according to the proposed relationship ${ }^{19}$ between the helical sense and the sign of pitch-band CD. Such a critical wavelength may exist below $300 \mathrm{~nm}$ in the homopolyribonucleotides examined above.

The chiral smectic $(\mathrm{Sm} \mathrm{C})$ phase also shows selective reflection like the cholesteric phase, ${ }^{20}$ and low molecular weight compounds show a pitchband $\mathrm{CD}$ in the ultraviolet-infrared region. ${ }^{21,22}$ From the fact that the compounds used in this study are of high molecular weight, the helical textures found may be of the cholesteric type (and not of the $\mathrm{Sm} C$ type). The sense of the helicoidal texture is left-handed in poly(A) and right-handed in poly(I), poly $(\mathrm{C})$, and poly $(\mathrm{U})$. Thus the sense of poly(A). $\operatorname{poly}(\mathrm{U})$ (and poly $(\mathrm{A}) \cdot 2 \operatorname{poly}(\mathrm{U})$ ) agrees with that of poly(U) but not of poly(A).

The pitch-band $\mathrm{CD}$ disappeared when the concentrated solutions became isotropic at high temperatures, above $5^{\circ} \mathrm{C}$ for poly $(\mathrm{U})$ and at $70^{\circ} \mathrm{C}$ for other polyribonucleotides.

\section{Visible Absorptivity}

Figure 6 summarizes the visible absorption spectra of $\mathrm{AO}$ in both isotropic and birefringent solutions. The intrinsic absorption of $\mathrm{AO}$ is observed in the wavelength region between 550 and $400 \mathrm{~nm}$. It can be seen that the pure AO solution (dotted line) shows an absorption maximum around $465 \mathrm{~nm}$. In dilute solutions $(0.5 \mathrm{vol} \%)$, a new absorption maximum appears around $500 \mathrm{~nm}$ for $\operatorname{poly}(A), \operatorname{poly}(\mathrm{G})$, and poly(I) and the original band remains as a shoulder around $470 \mathrm{~nm}$. As for poly $(C)$ and poly $(\mathrm{U})$, the maximum remains near $470 \mathrm{~nm}$ and the 


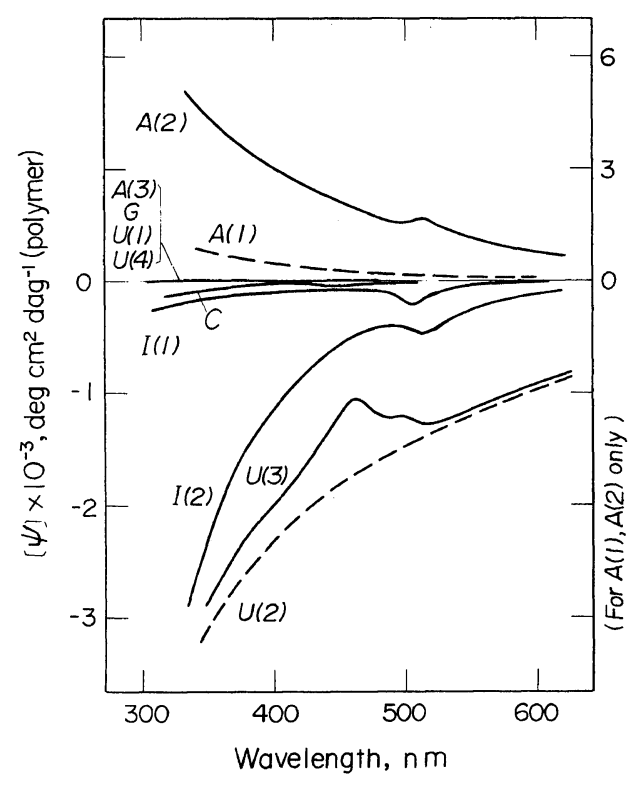

Figure 5. $\mathrm{CD}$ spectra of concentrated solutions. A, poly(A), (1) $10 \mathrm{vol} \%$, (2) $20 \mathrm{vol} \%+1 / 150 \mathrm{AO}$, (3) 15 $\mathrm{vol} \%+1 / 100 \mathrm{AO}\left(70^{\circ} \mathrm{C}\right) ; \mathrm{G}, \operatorname{poly}(\mathrm{G}), 30 \mathrm{vol} \%+1 / 100$ $\mathrm{AO} ; \mathrm{I}$, poly(I), (1) $13 \mathrm{vol} \%+1 / 80 \mathrm{AO}$, (2) $20 \mathrm{vol} \%+1 / 80$ $\mathrm{AO} ; \mathrm{C}$, poly(C), $50 \mathrm{vol} \%+1 / 90 \mathrm{AO} ; \mathrm{U}$, poly(U) $\left(2^{\circ} \mathrm{C}\right)$, (1) $19 \mathrm{vol} \%$, (2) $24 \mathrm{vol} \%$, (3) $24 \mathrm{vol} \%+1 / 100 \mathrm{AO}$, (4) 24 $\mathrm{vol} \%+1 / 100 \mathrm{AO}\left(22^{\circ} \mathrm{C}\right)$. Measured at $22^{\circ} \mathrm{C}$ unless otherwise specified. Dag, decagram $(10 \mathrm{~g})$.

band around $500 \mathrm{~nm}$ appears as a shoulder. In the poly(L-glutamic acid)-AO system, the three absorption bands at 492 ( $\alpha$-band), 470 ( $\beta$-band), and $450 \mathrm{~nm}$ ( $\gamma$-band) are attributed to monomeric $\mathrm{AO}$, dimeric $\mathrm{AO}$, and aggregated $\mathrm{AO}$, respectively. ${ }^{23}$ This assignment may be made to the present preparations as well.

The exact position and shape of absorption spectra vary depending on the polyribonucleotide tested, suggesting that AO interacts differently with different host polymers. At $70^{\circ} \mathrm{C}$ where the helical conformation is unfolded, the absorption of $\mathrm{AO}$ increases in intensity and, except for some cases, makes a slight blue shift (less than $5 \mathrm{~nm}$ ). The hyperchromic nature is typical of the unfolding of polymer helices ${ }^{24}$ and this might be the case also with the disorganization of the helical arrangement of the chromophore AO molecule which is considered to be arranged about the core of the polymer helices. The blue shift and a drastic increase in absorptivity around $500 \mathrm{~nm}$ are seen in the poly(C) spectrum; the origin is still to be seen.

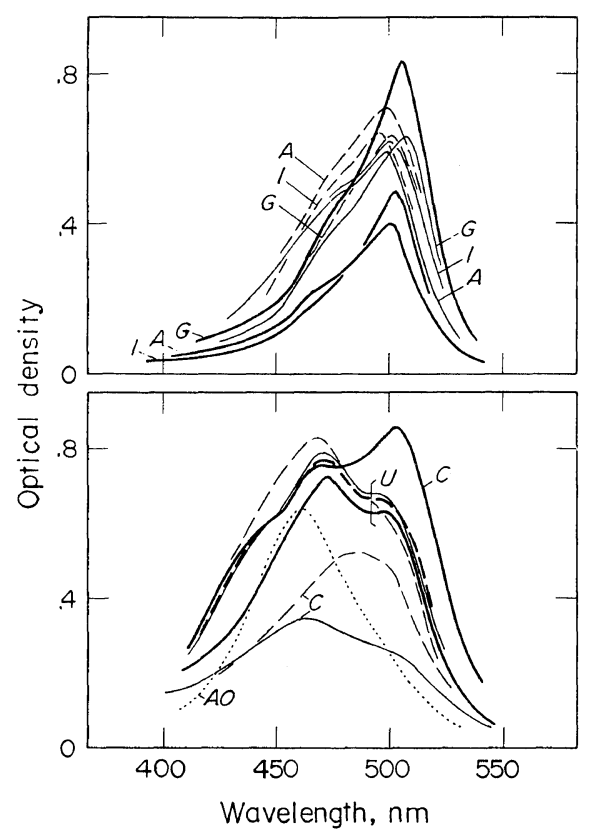

Figure 6. Visible absorption spectra of acridine orange in solutions of $A$, poly $(A) ; G, \operatorname{poly}(G) ; I$, poly(I); C, poly $(\mathrm{C})$; U, poly $(\mathrm{U})$.

[Thick lines] Concentrated solutions. Solid lines, liquid crystalline; broken line (only for $\mathrm{U}$ ), isotropic at $22^{\circ} \mathrm{C}$. Polymer concentrations in vol\%: A, 20; G, 10; I, 20; C, 35 ; U, 29. AO concentration and pathlength, varied.

[Thin lines] $0.5-\mathrm{vol}^{\%}$ solutions. Solid lines, obtained at $22^{\circ} \mathrm{C}$ except for $\mathrm{U}\left(2^{\circ} \mathrm{C}\right)$; broken lines, obtained at $70^{\circ} \mathrm{C}$ except for $U\left(22^{\circ} \mathrm{C}\right)$. AO concentration, $1 / 100$ except for U (1/80); pathlength, $1 \mathrm{~mm}$. Dotted line, pure AO solution $\left(0.008 \mathrm{wt}^{\mathrm{\%}} \mathrm{o}\right)$; pathlength, $1 \mathrm{~mm}$.

In concentrated birefringent solutions, the absorption curve of AO makes a slight red shift (less than $5 \mathrm{~nm}$ ), suggesting that the interaction between $\mathrm{AO}$ and the host polymer becomes stronger. In the poly $(C)$ solution, the shoulder at about $500 \mathrm{~nm}$ changes to a maximum. No red shift is observed in the poly $(G)$ solution. The polymer helices in the chiral texture, and accordingly the AO molecules bound to these polymer helices, are considered to orient in some specific way to the surface of the optical cell. Therefore the observed absorption intensity is only apparent and thus it should not be compared for the two states of polymer solution, isotropic and liquid crystalline.

\section{Induced Circular Dichroism}

The CD curves of the birefringent solutions con- 


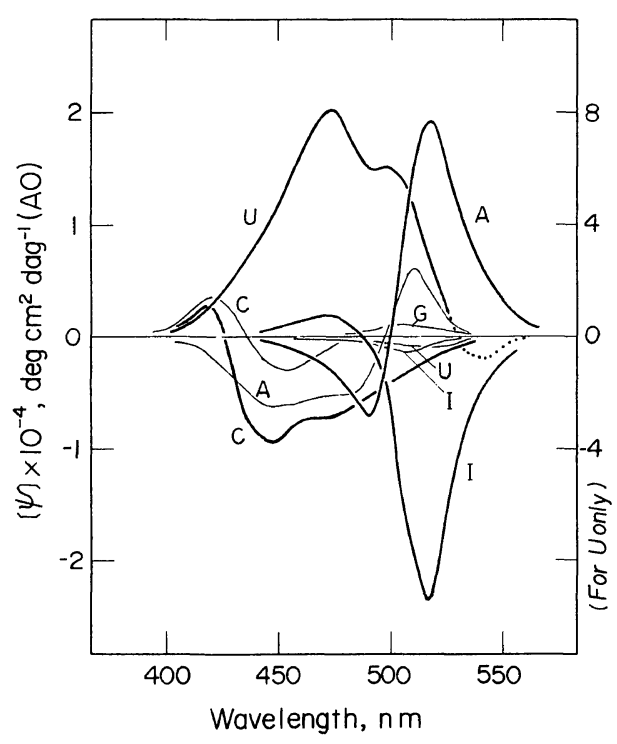

Figure 7. ICD spectra of acridine orange in polyribonucleotide solutions. Symbols are the same as in Figure 6 with a few exceptions; the polymer concentration was $50 \mathrm{vol} \%$ in $\mathrm{C}$ and $30 \mathrm{vol} \%$ in $\mathrm{U}$.

taining $\mathrm{AO}$ are not monotonic, suggesting the appearance of a new $C D$ (Figure 5). The wavelength region where the uneveness of the $\mathrm{CD}$ curves is observed coincides with the region where the intrinsic absorption of AO is observed. Since AO itself is achiral, this new CD must have been induced in the $\mathrm{AO}$ molecules by the dissymmetric field of the chiral mesophase according to the suggestion of Tsuchihashi and his coworkers ${ }^{25}$ for $\mathrm{AO}$ in the cholesteric liquid crystal of PBG.

The net induced circular dichroism (ICD) was roughly estimated by subtracting the pitch-band $\mathrm{CD}$ from the observed $\mathrm{CD}$, and the results are partially shown in Figure 7. When dissolved in a concentrated poly(A) or poly(U) solution, AO shows a main positive ICD with an additional negative ICD; the additional ICD in the poly(U) solution is not seen clearly. On the other hand, in the poly(I) or poly $(\mathrm{C})$ solution, AO shows a main negative ICD with an additional positive ICD. The ICD in the poly(I) solution is similar to that in the poly(A) solution except that the sign is reversed corresponding to the fact that signs of the pitchband $C D$ are opposite. The sign of the main ICD coincides with that of the pitch-band CD except in the $\operatorname{poly}(U)$ solution.
The ICD in the poly $(\mathrm{C})$ and poly(U) solutions are different from those of the poly(A) and poly(I) solutions. The former are located at shorter wavelengths than the latter. The shape of the ICD curve in the poly $(\mathrm{U})$ solution is somewhat similar to that of the intrinsic absorption curve of AO but not so in other polyribonucleotide solutions, and in the poly(C) solution a new ICD appears at about $450 \mathrm{~nm}$. The ICD in the poly $(G)$ solution was weak and hence concluded not to be induced by the liquid crystalline texture.

Hatano and his coworkers ${ }^{26}$ studied the ICD of achiral molecules in the chiral mesophase and found that when the chiral molecules are bound to the host molecules, the ICD curve changes in shape from that of the intrinsic absorption of the achiral molecules. This is exactly the case for AO dissolved in concentrated solutions of polyribonucleotides. When the achiral molecules are not bound to the host molecules, or in other words, when the CD is induced only by the dissymmetric field of the chiral mesophase, the shapes of these two curves are very similar. According to Saeva and his coworkers, ${ }^{27}$ the ICD sign of the transition moment orienting preferentially parallel to the long axis of the liquid crystal molecule coincides with that of the pitchband $C D$ when the reflective wavelength $\left(\lambda_{m}\right)$ is smaller than the wavelength of the intrinsic absorption, as in the present case. The experimental evidence for $A O$ in the poly(A), poly(I), and poly $(C)$ solutions may be considered to satisfy this condition. The experimental evidence for AO in the poly(U) solution that signs of the ICD and the pitch-band CD are opposite is still to be seen. At any rate, the appearance of ICD is reasonable since the polyribonucleotide solutions have chiral textures.

Since the AO molecules are bound to the host molecules, they show ICD even in dilute isotropic solutions (Figure 7). The intensity and shape of the ICD curves differ, depending on the polyribonucleotide solution in which AO is dissolved, indicating again that the interaction between $\mathrm{AO}$ and the host polymer helices varies with the polyribonucleotide. The intensity of ICD is weaker in poly $(G)$ and poly(I) solutions than in other polyribonucleotide solutions. Since the residue-to-dye ratio is high enough (40 or more), only a very small fraction of the residues of the polyribonucleotide molecule may combine AO molecules, espe- 


\section{E. IIZUKA}
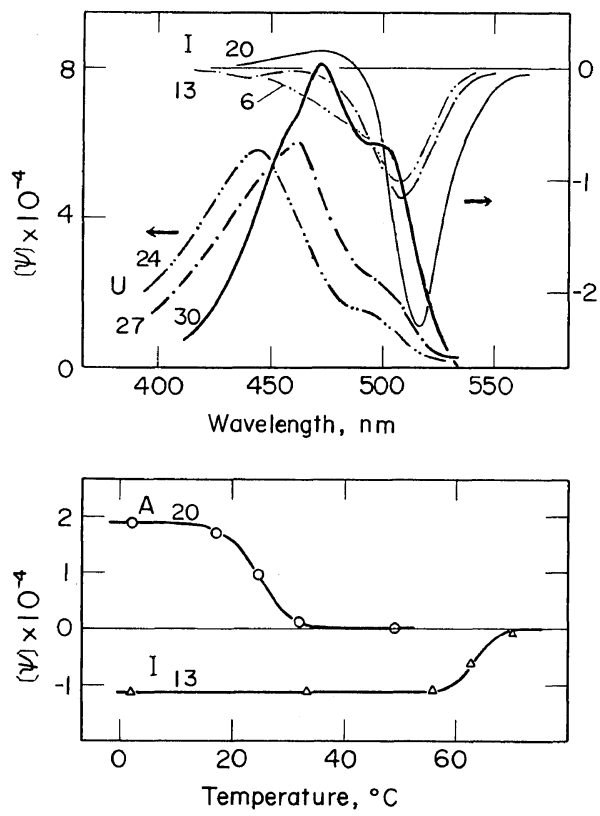

Figure 8. Effects of the polymer concentration and temperature on the ICD of acridine orange in solutions of A, poly(A); I, poly(I); U, poly(U). The temperature dependence was measured at a wavelength of $515 \mathrm{~nm}$ for $A$ and $505 \mathrm{~nm}$ for I. The figures next to the lines represent polymer concentrations in $\mathrm{vol}^{\%} \%$.

cially in these two polymer solutions.

Figure 8 shows the changes in ICD with an increase in polymer concentration and temperature. With increasing polymer concentration, the intensity of ICD increases and the ICD curve undergoes a red shift and a change in shape. This finding suggests that the interaction between $\mathrm{AO}$ and the host polymer helices becomes stronger with an increase in polymer concentration. When the temperature is raised, the intensity of ICD remains constant until the liquid crystal begins to dissolve and finally decreases to zero. The ICD in the poly(U) solution disappears at $5^{\circ} \mathrm{C}$ corresponding to the unfolding of the polymer helices and the disappearance of the liquid crystal structure.

\section{CONCLUSION}

Concentrated solutions of polyribonucleotides were liquid crystalline. The mesophase found in these polyribonucleotides except for $\operatorname{poly}(G)$ were chiral and probably of the cholesteric type. The helical sense of the chiral texture was left-handed in the poly(A) solution and right-handed in the poly(I), poly $(\mathrm{C})$, and poly $(\mathrm{U})$ solutions. $\mathrm{CD}$ was induced in an achiral reagent of acridine orange dissolved in liquid crystalline solutions, as may be expected for chiral textures of the liquid crystals. The interaction between acridine orange and the host polymer molecules is considered to vary with the polyribonucleotide.

Acknowledgments. The author wishes to express his appreciation to Professor J. T. Yang for kindly donating the polyribonucleotide specimens and to Professor M. Hatano of Tohoku University for his useful comments on the ICD results.

\section{REFERENCES}

1. E. Iizuka and J. T. Yang, in "Liquid Crystals and Ordered Fluids," Vol. 3, J. F. Johnson and R. S. Porter, Eds., Plenum Press, New York, N. Y., 1978, p 197.

2. E. Iizuka, Polym. J., 10, 293 (1978).

3. E. Iizuka and Y. Kondo, Mol. Cryst. Liq. Cryst., 51, 285 (1979).

4. G. C. Chen and J. T. Yang, Biophys. Chem., 1, 62 (1973).

5. M. J. B. Tunis-Schneider and M. F. Maestre, J. Mol. Biol., 52, 521 (1970).

6. C. Robinson, Trans. Faraday Soc., 52, 571 (1956).

7. M. B. Rhodes and R. S. Stein, J. Polym. Sci., A-2, 7, 1539 (1969).

8. E. Iizuka, T. Keira, and A. Wada, Mol. Cryst. Liq. Cryst., 23, 13 (1973).

9. M. Matsuo, F. Ozaki, H. Ueda, and T. Ogita, Polym. Prepr., Jpn., 28, 317 (1979).

10. E. Iizuka, Mol. Cryst. Liq. Cryst., 25, 287 (1974).

11. A. Rich, D. R. Davies, F. H. C. Crick, and J. D. Watson, J. Mol. Biol., 3, 71 (1961).

12. W. T. Astbury, Symp. Soc. Exp. Biol., I. Nucleic Acid, University Press, Cambridge, 1974, p 66

13. A. Rich, Biochim. Biophys. Acta, 29, 502 (1958).

14. E. O. Akinrimisi, C. Sander, and P. O. P. Ts'o, Biochemistry, 2, 340 (1963).

15. E. G. Richards, C. P. Flessel, and J. R. Fresco, Biopolymers, 1, 431 (1963).

16. M. N. Lipsett, Proc. Natl. Acad. Sci. U.S.A., 46, 445 (1960).

17. C. Robinson, Tetrahedron, 13, 219 (1961).

18. de Vries, HL., Acta Cryst., 4, 219 (1951).

19. T. Tachibana and E. Oda, Bull. Chem. Soc. Jpn., 46, 2583 (1973).

20. D. W. Berreman, Mol. Cryst. Liq. Cryst., 22, 175 (1973). 


\section{Polyribonucleotide Solutions}

21. K. Hori, Mol. Cryst. Liq. Cryst., 82, 13 (1982).

22. M. Hatano, Tohoku University, private communication, 1983.

23. M. Hatano, M. Yoneyama, and Y. Sato, Biopolymers, 12, 895 (1973).

24. S. Mii and R. C. Warner, Fed. Proc., 19, 317 (1960).
25. N. Tsuchihashi, H. Nomori, M. Hatano, and S. Mori, Chem. Lett., 823 (1974).

26. For example: Y. Sato and M. Hatano, Makromol. Chem., 183, 997 (1982).

27. F. D. Saeva, P. E. Sharpe, and G. R. Olin, J. Am. Chem. Soc., 95, 7656 (1973). 